\title{
Predicting Readiness to Attend an Interdisciplinary Pain Management Program: What's better for Clinical Decision-Making? Clinical J udgment or a Patient Self- Report Questionnaire?
}

\author{
Hapidou EG ${ }^{1,2,3 *}$, Mazzocato $\mathrm{GL}^{4}$ and Culig KM $\mathrm{K}^{3}$ \\ ${ }^{1}$ Michael G. De Groote Pain Clinic, Hamilton Health \\ Sciences, Canada \\ ${ }^{2}$ Psychology, Neuroscience, \& Behaviour, McMaster \\ University, Canada \\ ${ }^{3}$ Bachelor of Health Sciences (Honours Program), \\ McMaster University, Canada \\ ${ }^{4}$ Occupational Therapy, Hamilton Health Sciences \\ *Corresponding author: Hapidou EG, Michael G. De \\ Groote Pain Clinic, Hamilton Health Sciences, Canada
}

Received: August 04, 2017; Accepted: September 07, 2017; Published: September 14, 2017

\begin{abstract}
Background: Chronic Pain (CP) can have a substantial negative impact on one's life. Patients often seek Pain Management Programs (PMPs) as a means to treat their CP condition. The Michael G. DeGroote Pain Clinic, located in Hamilton, Ontario is a PMP that admits patients based on a variety of clinically important factors. Patients assessed are either recommended or not recommended into the program after consideration of these factors.
\end{abstract}

Aims: The objective of this study was to examine if readiness, as assessed by the Pain Stages of Change Questionnaire (PSOCQ), is associated with a clinical judgment of readiness in recommending a person into a PMP. Additionally, to investigate whether PSOCQ scores or clinician judgment predicted readiness to attend a PMP.

Methods: One-hundred and eight people were approached and recruited to this study. The 108 patients referred to the PMP in Ontario, were either recommended or not recommended into a PMP after completing an initial assessment. Associations between clinician rating, recommendation status and PSOCQ subscale scores were analyzed using independent t-tests, Pearson Correlation, and Stepwise Regression. We hypothesize that readiness assessed by the PSOCQ would be associated with clinical judgment of readiness in recommending a person into the PMP but that clinical judgment would be superior in predicting readiness to attend a PMP rather than the PSOCQ scores.

Results: Those recommended to the PMP had higher assessor ratings, lower pre-contemplation and higher contemplation scores. There were significant relationships between the clinician's rating, pre-contemplation, contemplation, and recommendation status. Stepwise regression methods revealed that while there may be benefit to using questionnaire measures of readiness to change, clinical judgment was the best predictor for recommendation into the PMP.

Conclusions: Clinical judgment in the initial assessment process was superior in clinical decision-making regarding a patient's readiness to attend a PMP, as compared to a self-report questionnaire.

Keywords: Chronic pain; Readiness; PSOCQ

\section{Introduction}

Individuals who suffer from chronic pain $(\mathrm{CP})$ vary in their readiness to change their approach in dealing with their pain. Readiness is defined as "the degree to which a person accepts personal responsibility for pain control, and the extent to which they are thinking about changing their behaviour to cope with their pain" [1]. According to the transtheoretical model of behaviour change, individuals are seen as progressing through a number of stages regarding decisions to change [2]. The idea of "stages of change" being applied to chronic pain management stimulated research by Kerns and colleagues $[1,3]$, who sought to determine the relevance of readiness to change when considered with the multidisciplinary cognitive behavioural approach to pain management [4]. The pain "stages of change" model proposes that individuals vary in their readiness to adopt a self-management approach to chronic pain and that all CP patients can be categorized into one of four discrete stages of change: pre-contemplation, contemplation, action, and maintenance. The model also proposes that individually tailored treatment approaches can be implemented according to the stage of change that an individual belongs to.

As an example, those in earlier stages of change (i.e., precontemplation and contemplation) may benefit more from cognitive interventions including education about chronic pain. In comparison, those in later stages of change (i.e., action and maintenance) are more likely to benefit from skills training, relaxation training, exercise and relapse prevention strategies.
Austin J Anesthesia and Analgesia - Volume 5 Issue 2 - 2017 ISSN : 2381-893X | www.austinpublishing group.com

Hapidou et al. (@) All rights are reserved
Citation: Hapidou EG, Mazzocato GL and Culig KM. Predicting Readiness to Attend an Interdisciplinary Pain Management Program: What's better for Clinical Decision-Making? Clinical Judgment or a Patient Self-Report Questionnaire?. Austin J Anesthesia and Analgesia. 2017; 5(2): 1057. 
The Pain Stages of Change Questionnaire (PSOCQ) validly and reliably assesses readiness to change in chronic pain patients [3]. It measures four stages according to degree of readiness to adopt a self-management approach to chronic pain: 1) Pre-contemplation (Precont) is the belief that management of the pain problem is medical and should be the responsibility of medical professionals to alleviate; 2) Contemplation (Cont) is the consideration of adopting a self-management approach but reluctance to give up the pursuit of a medical solution; 3) Action is the beginning attempts to improve selfmanagement skills; and 4) Maintenance (Maint)is the commitment to pain self-management.

The use of a multidisciplinary pain management program has more recently been found to improve an individual's readiness to change in self-regulating their chronic condition [4]. In particular, patients who underwent treatment in this PMP significantly lowered their Precont subscale scores, while significantly increasing their Action and Maint scores [5]. In addition, Kerns and Rosenberg [1] demonstrated the predictive ability of the PSOCQ in determining engagement in treatment. However, these researchers were not able to demonstrate the predictive ability of the PSOCQ in determining pain outcomes. The PSOCQ identifies the primary stage of change of a patient and can predict their completion of outpatient and inpatient cognitive behavioural programs $[1,6,7]$ as well as improved coping [8]. Consistent with past studies, motivational readiness predicted treatment completion as well as functional rehabilitation outcomes in CP patients who experienced a motor vehicle accident [9]. Further, a recent study provided evidence for the tool's cross-cultural reliability and validity in an Italian-speaking cohort [10]. Another study examined the influence of readiness to change in predicting treatment outcomes in an adolescent population [11]. From this exploration, the reliability and validity of the parent and adolescent adapted PSOCQ scale were demonstrated.

Recently, a study was conducted to investigate the psychometric properties of the PSOCQ scale in a pediatric CP population in order to provide further cross-validation of the subscale measures across diverse patient groups [12]. Results from this study indicate that the psychometric proprieties (e.g., internal consistency, testretest stability, and construct validity) were robust in this sample of patients. In another investigation, researchers attempted to observe if PSOCQ scores were a reliable predictor of completing treatment and were associated with treatment outcomes in a sample of 261 patients living with chronic non-malignant pain [13]. The authors reported the predictive value of the PSOCQ in determining which patients were more likely to complete treatment. In addition, the authors found that those who progressed through the stages of change, in contrast to those who did not progress or reverted, demonstrated significant improvement in function (measured by the SF-36 version 2), and mood outcomes (e.g., mood disturbance, measured by the SF-36 version 2 mental health subscale). Despite this, no significant improvements in pain were reported for those who progressed through the PSOCQ stages versus those that did not progress or regressed.

The Cont subscale of the PSOCQ has been found to be one of the predictors of functional outcome three months into treatment for chronic pain [14]. However, classification of patients based on scores on a single subscale has been criticized [15]. The PSOCQ has been used to identify subgroups (clusters) of individuals seeking treatment for chronic pain; subgroups differed according to scores on the Survey of Pain Attitudes but not in terms of demographics, pain or disability [16]. However, irrespective of which method is used to classify individuals into discrete stages or subgroups, the PSOCQ has been found to be insufficient in terms of determining inclusion or exclusion criteria for enrolment in a cognitive-behavioural program [6]. Moreover, researchers have questioned the external validity of the PSOCQ by showing that a self-efficacy measure was a better predictor of outcome than the PSOCQ [17]. In addition, others have found that adherence to therapist recommendations for practicing coping skills mediated readiness to change and goal accomplishment in a chronic pain management program [18]. It has also been suggested that while psychometric tools are valuable in assessment, they should not be considered a reliable substitute for the clinical interviewing process [19].

However, there is paucity of research in examining readiness to change in the context of clinical decision-making. This is much needed in light of the fact that many individuals either do not improve, or complete treatment unsuccessfully [20]. Dropout rates from cognitive-behavioural pain management programs can vary between $5 \%$ to $70 \%$ [21]. Therefore, there have been repeated calls to identify consistent and reliable pre-treatment patient indicators predictive of the success of chronic pain management programs. One such indicator may be readiness to change behaviour and adopting a self-management approach to pain.

\section{Materials and Methods}

\section{Participants}

A convenience sample of 108 adults (54 female) who were assessed in the PMP participated in this study. Table 1 lists the demographic variables of the participants. The majority of individuals in this sample sustained injuries in work-related or motor vehicle accidents, which acted as an antecedent to their CP condition. This cohort of patients had a variety of chronic pain problems, including generalized and regionalized body pain. The majority of participants were taking medications such as opioids, anti-depressants, antiinflammatories and sleep medications prior to assessment into the PMP. All participants provided written informed consent before participating in the PMP assessment and ongoing program research. Ethics approval was obtained by the Hamilton Integrated Research Ethics Board (HiREB) of Hamilton Health Sciences.

\section{Pain management program}

The four-week interdisciplinary, multimodal chronic pain management program with a cognitive-behavioural orientation (previously known as the Chronic Pain Management Unit), is now part of the Michael G. De Groote Pain Clinic. Activities in the PMP are designed to teach and enable patients with heterogeneous pain problems to adopt a self-management approach to chronic pain. Participants referred to the PMP had exhausted other forms of pain management treatments receiving little to no pain relief. Once individuals are referred to the PMP they attend a group orientation session that introduces them and their families to chronic pain concepts and self-management approaches. Those interested in the 
Table 1: Patient Demographics.

\begin{tabular}{|c|c|}
\hline Patient Characteristic & Participants $(n=108)$ \\
\hline \multicolumn{2}{|l|}{ Recommended } \\
\hline Yes & 78 \\
\hline No & 30 \\
\hline \multicolumn{2}{|l|}{$\operatorname{Sex}(n)$} \\
\hline Male & 54 \\
\hline Female & 54 \\
\hline \multicolumn{2}{|l|}{ Marital Status (n) } \\
\hline Married & 63 \\
\hline Single & 15 \\
\hline Divorce/Separated/Widowed & 15 \\
\hline \multicolumn{2}{|l|}{ Place of Birth (n) } \\
\hline Canada & 66 \\
\hline Elsewhere & 25 \\
\hline \multicolumn{2}{|l|}{ Children } \\
\hline Yes & 75 \\
\hline No & 18 \\
\hline Education, years, mean \pm SD & $12.59 \pm 2.98$ \\
\hline Age, years, mean \pm SD & $44.82 \pm 8.93$ \\
\hline Years in Canada, mean \pm SD & $39.02 \pm 12.84$ \\
\hline Number of injuries, mean \pm SD & $1.95 \pm 1.74$ \\
\hline Pain duration (months), mean \pm SD & $54.78 \pm 63.03$ \\
\hline Time off work (months), mean \pm SD & $32.94 \pm 52.62$ \\
\hline Number of Primary Care Visits, mean \pm SD & $44.18 \pm 122.89$ \\
\hline Number of Specialist Visits, mean \pm SD & $6.11 \pm 12.27$ \\
\hline Number of Emergency Room Visits, mean \pm SD & $2.41 \pm 9.32$ \\
\hline
\end{tabular}

program were assessed by one of the health care providers through a semi-structured interview process. After completion of the group orientation session and semi-structured interview, recommendations for admission were made at the Intake Team meeting where all assessors were present. Assessors at the Intake Team Meeting use their clinical judgment to decide if the CP patient is well suited to take part in the Program. This usually entails that the individual is willing and motivated to adopt an active rehabilitation approach to managing pain. Moreover, this includes goal setting and the ability to exercise daily. Openness to discuss and accept the influence of psychological factors such as emotions and stress on pain also is a necessary criterion for recommendation. Individuals are then scheduled to attend the PMP following approval by their referring agency (WSIB, motor-vehicle insurance company, etc.).

\section{Assessors and procedures}

Directly following the semi-structured interview with the patient, one of nine clinicians in the interdisciplinary PMP (five occupational therapists, two social workers, two psychologists) provided ratings of readiness on a 10-point scale (1: not ready to 10 : completely ready) devised for this study. Prior to their interview, all patients completed the PSOCQ as part of their assessment process in the PMP. The clinical team did not see the results of the PSOCQ prior to providing their recommendation. The assessors were blinded as to the patient's

Table 2: Descriptive Statistics for Study Variables (n=91).
\begin{tabular}{|c|c|c|c|}
\hline & $\begin{array}{c}\text { Not Recommended } \\
\text { to PMP (n=26), } \\
\text { mean (SD) }\end{array}$ & $\begin{array}{c}\text { Recommended to } \\
\text { PMP (n=65), } \\
\text { Mean (SD) }\end{array}$ & Significance \\
\hline Pre-contemplation & $3.37 \pm 0.59$ & $2.98 \pm 0.64$ & $0.009^{*}$ \\
\hline Contemplation & $3.41 \pm 0.63$ & $3.82 \pm 0.49$ & $0.002^{\star}$ \\
\hline Action & $2.98 \pm 0.64$ & $3.13 \pm 0.84$ & 0.419 \\
\hline Maintenance & $3.01 \pm 0.47$ & $3.19 \pm 0.81$ & 0.0992 \\
\hline Rating & $4.08 \pm 2.45$ & $7.21 \pm 1.71$ & 0 \\
\hline
\end{tabular}

Table 3: Correlation Matrix.

\begin{tabular}{|c|c|c|c|c|c|c|c|}
\hline & & Precont & Cont & Action & Maint & Rating & Recomm \\
\hline Precont & $\mathrm{r}$ & 1 & & & & & \\
\hline & $\mathrm{p}$ & & & & & & \\
\hline Cont & $\mathrm{r}$ & $-.237^{\star}$ & 1 & & & & \\
\hline & $\mathrm{p}$ & 0.018 & & & & & \\
\hline Action & $\mathrm{r}$ & $-.271^{\star \star}$ & $.331^{\star \star}$ & 1 & & & \\
\hline & $\mathrm{p}$ & 0.007 & 0.001 & & & & \\
\hline Maint & $\mathrm{r}$ & -0.184 & $.228^{\star}$ & $.795^{\star \star}$ & 1 & & \\
\hline & $\mathrm{p}$ & 0.069 & 0.023 & 0 & & & \\
\hline Rating & $\mathrm{r}$ & $-.255^{\star}$ & $.356^{\star *}$ & 0.169 & 0.167 & 1 & \\
\hline & $\mathrm{p}$ & 0.012 & 0 & 0.1 & 0.103 & & \\
\hline Recomm & $\mathrm{r}$ & $.272^{\star *}$ & $-.327^{\star \star}$ & -0.086 & -0.062 & $-.591^{\star \star}$ & 1 \\
\hline & $\mathrm{p}$ & 0.009 & 0.002 & 0.419 & 0.561 & 0 & \\
\hline
\end{tabular}

${ }^{*}$ Correlation is significant at the $p<0.05$ level.

${ }^{* *}$ Correlation is significant at the $p<0.01$ level.

PSOCQ results at the time of the semi-structured interview and recommendation to the PMP. The final decision to recommended or not recommended the patients to the PMP was made after the presentation of their cases to the Intake Team and subsequent discussion among all staff members performing assessments on the patient's readiness for the program.

\section{Statistical analysis}

Independent $\mathrm{t}$-tests were used to calculate the differences in PSOCQ subscales scores (i.e., Precont, Cont, Action and Maint) and clinical judgment (i.e., recommended versus not recommended into the PMP). Pearson correlation analysis was used to determine the strength of the relationship between the patient self-reported PSOCQ subscale scores, the assessor's rating, and recommendation status (recomm). Stepwise regression was performed to predict recommendation status (recommended versus not recommended) from five independent variables: The assessor rating and each of the four PSOCQ subscales. Seventeen patients (16\%) had incomplete PSOCQ scores and their data were not included in the analysis.

\section{Results}

\section{Independent t-test}

Descriptive statistics are presented in Table 2. There were no differences in demographic characteristics between those recommended and those not recommended into the PMP (Table 1). Results from the independent $t$-test yielded a significantly lower mean $( \pm$ SD) Precont score for those recommended $(2.98 \pm 0.64)$ versus not recommended $(3.37 \pm 0.59)$ into the PMP $(\mathrm{p}=0.009)$. Those not 
Table 4: a-d. Stepwise Regression Analysis.

4a. Variables Entered/Removed.

\begin{tabular}{|c|c|c|}
\hline Model & Variables Entered & Method \\
\hline 1 & RATING & Stepwise (Criteria: Probability of F-to-enter< $=.050$. Probability-of-F-to-remove >=.100 \\
\hline
\end{tabular}

4b. Model Summary.

\begin{tabular}{|c|c|c|c|c|}
\hline Model & R & R Square & Adjusted R Square & Std. Error of the Estimate \\
\hline 1 & $0.591(\mathrm{~A})$ & 0.349 & 0.342 & 0.36542 \\
\hline
\end{tabular}

4c. Co-efficients

4c. Co-efficients.
\begin{tabular}{|c|c|c|c|c|c|}
\hline \multirow{2}{*}{ Model } & & \multicolumn{2}{|c|}{ Unstandardized Coefficients } & \multicolumn{2}{|c|}{ Standardized Coefficients } \\
\cline { 3 - 5 } & & B & Std. Error & Beta \\
\hline 1 & (constant) & 1.984 & 0.11 & 0 \\
\hline & RATING & -0.111 & 0.016 & -0.591 \\
\hline
\end{tabular}

a. Dependent Variable: RECOMMEND

4d. Excluded Variables.

\begin{tabular}{|c|c|c|c|c|}
\hline Model & & Beta in & $\mathbf{t}$ & Sig. \\
\hline 1 & PRECONT & $.095(\mathrm{a})$ & 1.066 & 0.29 \\
\hline & CONT & $-.120(\mathrm{a})$ & -1.296 & 0.198 \\
\hline & ACTION & $0.13(\mathrm{a})$ & 0.152 & 0.879 \\
\hline & MAINT & $0.045(\mathrm{a})$ & 0.516 & 0.607 \\
\hline
\end{tabular}

a. Predictors in the Model: (Constant), RATING.

b. Dependent Variable: RECOMMEND.

recommended for the PMP also had a significantly lower mean $( \pm S D)$ Cont scores $(3.41 \pm 0.63)$ than those recommended $(3.82 \pm 0.49, \mathrm{p}=$ 0.002) (Table 2).

Finally, the mean $( \pm S D)$ assessor rating was significantly higher in the recommended group of participants $(7.21 \pm 1.71)$ versus those not recommended $(4.08 \pm 2.45, \mathrm{p}=000)$. No significant differences were detected between those recommended versus not recommended in the Maint and Action subscales.

\section{Pearson correlation}

The Correlation Matrix between the patient self-reported PSOCQ subscale scores and assessor rating is presented in Table 3. There were significant relationships between the assessor rating and recommendation status $(\mathrm{r}=-.591, \mathrm{p}<0.01)$, assessor's rating and Precont score $(-.255, \mathrm{p}<0.01)$, assessor rating and Cont score $(\mathrm{r}=.356$, $\mathrm{p}<0.01)$, recommendation status and Precont score $(\mathrm{r}=.272, \mathrm{p}<0.01)$, and recommendation status and Cont score $(\mathrm{r}=-3.27, \mathrm{p}<0.01)$.

\section{Stepwise regression}

Results of the stepwise regression are presented in Table 4a4d. Table $4 \mathrm{a}$ shows that clinician rating (RATING) was the only independent variable used to build the model for the dependent variable of recommendation status (i.e. RECOMMEND). Table $4 \mathrm{~b}$ shows the correlation between the clinician rating included in the model (i.e. RATING) and recommendation status (i.e. RECOMMEND). Clinician rating was positively correlated with recommendation status $(\mathrm{r}=0.591)$. Table $4 \mathrm{c}$ displays information that is used to inform the linear regression equation. Clinician rating (i.e., RATING) showed a $\beta$ coefficient $=-.111(\mathrm{p}<0.001)$ in relation to recommendation status (i.e. RECOMMEND). Table $4 \mathrm{~d}$ outlines the variables that did not reach significance $(p>0.05)$ in order to be included in the regression model. These included the Precont, Cont,
Action, and Maint subscales.

\section{Discussion}

The present study demonstrates that clinical judgment in determining readiness and recommendation to a PMP supersedes that of the PSOCQ. This is especially pertinent after considering the results presented in Table $4 \mathrm{a}-4 \mathrm{~d}$. Clinician rating was the only variable that entered the model, and thus was the only variable that significantly $(\mathrm{p}<0.05)$ predicted recommendation status. Results from Table $4 \mathrm{~b}$ demonstrate that $35 \%$ of the variation in recommendation status can be attributed to clinician rating. This strong association is intuitive, and provides support to the research hypothesis. None of the PSOCQ subscales were included in the final stepwise regression model. This suggests that the Precont, Cont, Action and Maint subscales were not sufficient in predicting recommendation into a PMP.

Therefore, it is clear that the assessor's rating alone best predicted the recommendation of an individual with a $\mathrm{CP}$ condition to the PMP. Even though the assessed patients also had significantly lower pre-contemplation and higher contemplation scores, the addition of these variables did not add significantly to the regression equation after accounting for the influence of the assessor rating.

Like in many other studies, the correlation between action and maintenance subscales is very high $[3,7,8,17]$. Also, despite the fact that contemplation was significantly associated with the assessor rating, this still does not support the finding by Carr and colleagues [22], that contemplation may have particular value in predicting who may or may not be ready to participate in a self-management program.

This finding highlights the importance of clinical judgment in determining patient readiness to attend a PMP. Though the PSOCQ may be an inexpensive and easily administered tool in determining aspects of one's readiness, it seems that it is not an adequate substitute to clinical decision-making. This is supported by the fact that patients recommended to the program had significantly higher assessor ratings than did those not recommended. Importantly, these differences between recommendation status groups (recommended versus not recommended) were much more pronounced for assessor rating than they were between the other Precont, Cont, Action and Maint subscales. 
Ninety-one of the 108 patients initially enrolled in the study filled out all patient questionnaires and participated throughout the study. Despite the fact that data from 17 patients (16\%) were not included in the data analysis, this is unlikely to bias the results in a significant way. Reasons for missing data may include failure to fill out the entire PSOCQ form (e.g. leaving question (s) blank), the presence of a language barrier making it difficult to complete the entire questionnaire validly, or not completing the numerical question score properly (e.g. answering qualitatively).

Taken together, these results point to the value of clinical judgment in the initial assessment process as a much superior variable in clinical decision-making regarding a patient's readiness to attend a self-management program, as compared to the PSOCQ. Results also confirm the cautionary point made by the originators of the PSOCQ and others as it not being used for clinical decision- making in a PMP $[1,6]$. Based on the present results, a client's readiness to adopt a selfmanagement program as measured by the PSOCQ should not be used alone to grant them recommendation into a PMP even though it is associated with and can be, in and of itself, a pain management outcome $[23,24]$. Moreover, it has been suggested that the PSOCQ might be better conceptualized as a measure representing a cognitive shift in perspective perhaps in thinking about alternative ways of dealing with the pain problem rather than a readiness to adopt specific coping behaviors or actions [22].

\section{Acknowledgement}

We would like to thank Lisa Patterson for her editorial assistance.

\section{References}

1. Kerns RD, Rosenberg R. Predicting responses to self-management treatments for chronic pain: application of the pain stages of change model. Pain. 2000; 84: 49-55.

2. Prochaska J, Diclemente C. Stages and processes of self-change of smoking: toward an integrative model of change. J Consult Clin Psychol. 1983; 51: 390 395.

3. Kerns RD, Rosenberg R, Jamison RN, Caudill MA, Haythornthwaite J. Readiness to adopt a self- management approach to chronic pain: the Pain Stages of Change Questionnaire (PSOCQ). Pain. 1997; 72: 227-234.

4. Turk DC, Meichenbaum D, Genest M. Pain and behavioral medicine: A cognitive-behavioral perspective. Guilford Press; 1983.

5. Dysvik E, Kvaløy JT, Stokkeland R, Natvig GK. The effectiveness of a multidisciplinary pain management programme managing chronic pain on pain perceptions, health-related quality of life and stages of change-a nonrandomized controlled study. International Journal of Nursing Studies. 2010; 47: 826-835.

6. Biller N, Arnstein P, Caudill MA, Federman CW, Guberman C. Predicting completion of a cognitive-behavioral pain management program by initial measures of a chronic pain patient's readiness for change. The Clinical Journal of Pain. 2000; 16: 352-359.

7. Burns JW, Glenn B, Lofland K, Bruehl S, Harden RN. Stages of change in readiness to adopt a self-management approach to chronic pain: the moderating role of early-treatment stage progression in predicting outcome. Pain. 2005; 115: 322-331.
8. Jensen MP, Nielson WR, Romano JM, Hill ML, Turner JA. Further evaluation of the pain stages of change questionnaire: is the transtheoretical model of change useful for patients with chronic pain? Pain. 2000; 86: 255-264.

9. Tkachuk GA, Marshall JK, Mercado AC, Murtry BM, Stockdale-Winder F. Readiness for change predicts outcomes of functional rehabilitation following motor vehicle accident. Journal of Occupational Rehabilitation. 2012; 22: 97 104.

10. Monticone M, Ferrante S, Ferrari S, Mugnai R, Pillastrini P, Rocca B, et al. Development of the Italian version of the Pain Stages of Change Questionnaire in patients with chronic low back pain: cross-cultural adaptation, confirmatory factor analysis, reliability and validity. International Journal of Rehabilitation Research. 2014; 37: 205-211.

11. Guite JW, Logan DE, Simons LE, Blood EA, Kerns RD. Readiness to change in pediatric chronic pain: Initial validation of adolescent and parent versions of the Pain Stages of Change Questionnaire. PAIN®. 2011; 152: 2301-2311.

12. Evans JR, Mano KJ, Guite JW, Weisman SJ, Hainsworth KR. Psychometric properties of the pain stages of change questionnaire: new insights on the measurement of readiness to change in adolescents, mothers, and fathers. The Journal of Pain. 2015; 16: 645-656.

13. Gersh E, Arnold C, Gibson SJ. The relationship between the readiness for change and clinical outcomes in response to multidisciplinary pain management. Pain Medicine. 2011; 12: 165-172.

14. Hankin HA, Killian CB. Prediction of functional outcomes in patients with chronic pain. Work. 2004; 22: 125-130.

15. Dijkstra A, Vlaeyen JW, Rijnen $\mathrm{H}$, Nielson W. Readiness to adopt the selfmanagement approach to cope with chronic pain in fibromyalgic patients. Pain. 2001; 90: 37-45.

16. Kerns RD, Wagner J, Rosenberg R, Haythornthwaite J, Caudill-Slosberg M Identification of subgroups of persons with chronic pain based on profiles on the pain stages of change questionnaire. Pain. 2005; 116: 302-310.

17. Strong J, Westbury K, Smith G, McKenzie I, Ryan W. Treatment outcome in individuals with chronic pain: Is the Pain Stages of Change Questionnaire (PSOCQ) a useful tool?. Pain. 2002; 97: 65-73.

18. Heapy A, Otis J, Marcus KS, Frantsve LM, Janke EA, Shulman M, et al. Intersession coping skill practice mediates the relationship between readiness for self-management treatment and goal accomplishment. Pain. 2005; 118: 360-368.

19. Jones-Hiscock C. Using depression inventories: Not a replacement for clinical judgment. Canadian Journal of Psychiatry. 2004; 49: 646

20. Turk DC, Rudy TE. Neglected factors in chronic pain treatment outcome studies-referral patterns, failure to enter treatment, and attrition. Pain. 1990; 43: 7-25.

21. Turk DC, Rudy TE. Neglected topics in the treatment of chronic pain patientsrelapse, noncompliance, and adherence enhancement. Pain. 1991; 44: 5-28.

22. Carr JL, Moffett JA, Sharp DM, Haines DR. Is the Pain Stages of Change Questionnaire (PSOCQ) a useful tool for predicting participation in a selfmanagement programme? Further evidence of validity, on a sample of UK pain clinic patients. BMC Musculoskeletal Disorders. 2006; 7: 101.

23. Hapidou EG, Abbasi, H. Readiness to adopt a self-management approach to chronic pain and pain management outcomes. Poster presented at: $3^{\text {rd }}$ World Congress World of Institute of Pain; 2004.

24. Williams RM, Hapidou EG, Lin CY, Abbasi H. Examining the pain stages of change questionnaire in chronic pain. Physiotherapy Canada. 2007; 59: 132-141.
Austin J Anesthesia and Analgesia - Volume 5 Issue 2 - 2017 ISSN : 2381-893X | www.austinpublishing group.com Hapidou et al. (C) All rights are reserved
Citation: Hapidou EG, Mazzocato GL and Culig KM. Predicting Readiness to Attend an Interdisciplinary Pain Management Program: What's better for Clinical Decision-Making? Clinical Judgment or a Patient Self-Report Questionnaire?. Austin J Anesthesia and Analgesia. 2017; 5(2): 1057. 